\title{
INVESTIGATION OF SPECTRAL CHARACTERISTICS OF CARBONATE ROCKS - A CASE STUDY ON POSHT MOLEH MOUNT IN IRAN
}

\author{
A. Imanian ${ }^{1}$, M. H. Tangestani ${ }^{1}$, A. Asadi ${ }^{2}$ \\ ${ }^{1}$ Department of Earth Sciences, Faculty of Sciences, Shiraz University, Shiraz, Fars, Iran - \\ (a.imanian@shirazu.ac.ir \& tangstan@shirazu.ac.ir) \\ ${ }^{2}$ Geological and Mining Engineering and Sciences Department, Michigan Technological University, \\ Houghton, MI, USA - (aasadi@mtu.edu)
}

KEY WORDS: Geological Remote Sensing, Multi Spectral Image, Lithological Mapping, Carbonate Rocks

\begin{abstract}
:
Recent developments in the image processing approaches and the availability of multi and/or hyper spectral remote sensing data with high spectral, spatial and temporal resolutions have made remote sensing technique of great interest in investigations of geological sciences. One of the biggest advantage of the application of remote sensing in geology is recognizing the type of unknown rocks and minerals. In this study, an investigation on spectral features of carbonate rocks (i.e. calcite, dolomite, and dolomitized calcite) were done in terms of main absorptions, the reasons of those absorptions and comparison of these absorption with Johns Hopkins University (JHU) spectral library and laboratory spectra of Analytical Spectral Devices (ASD) instrument. For this purpose, we used the VNIR and SWIR bands of ASTER and OLI datasets. Finally, we applied the Spectral Analyst Algorithm in order to comparison between the obtained spectra from ASTER dataset and carbonate spectra of JHU spectral library.
\end{abstract}

\section{INTRODUCTION}

The first earth observation satellite was launched into space by the United States on July 23, 1972, named ERTS which later renamed Landsat 1 . During the past several years, different satellites have been launched into the space that advanced sensors were embedded in them.

These days, the application of satellite imagery data have an important role in recognizing and separating different rock units. Remote sensing can study and analyse the spectral and spatial connection of different geological phenomena from a so far distance.

The main advantages of the remote sensing technique in geologic applications are providing information at different spectral and spatial resolutions, wide coverage, recognizing and separating rock units, preparation of the hazard maps, faults and fractures maps (Gupta, 2017).

This study aims to compare the capability of OLI and ASTER sensors in discriminating various carbonate minerals. To carry out this study, rock samples have been collected in the study area and their spectra were measured by an ASD instrument. The composition of rocks was identified in the laboratory.

Then the measured rock spectra were resampled to OLI and ASTER sensors to see if there are any useful information that might be used to distinguish various carbonate minerals by these two sensors.

\section{STUDY AREA}

The studied area in this research is located to the north of Shiraz city in Fars province, Iran (29 $37^{\prime} 40^{\prime \prime}$ to $29^{\circ} 42^{\prime} 40^{\prime \prime}$ North and $52^{\circ} 28^{\prime} 55^{\prime \prime}$ to $52^{\circ} 35^{\prime} 09^{\prime \prime}$ ' East).
This region has an approximate area of 30 square kilometers and the maximum height of 2100 meters above the sea level

When considering the type of petrographic coverage, the region is completely formed of carbonate rocks including calcite, dolomite and dolomitized calcite and other calcareous compounds such as marl, lime and so on. Vegetation cover in the domain area is abundant, but in the mountains, the region is poorly vegetated with thin bushes, grasses, and brushwood (Figure 1).

The study area is a part of the simple fold-thrust belt of Zagros and it is consisting of three geological formations named Asmari calcareous formation, Jahrom calcareous-dolomitic formation, and Quaternary sediments. Figure 2 shows the 1:100000 geology map of the studied area.

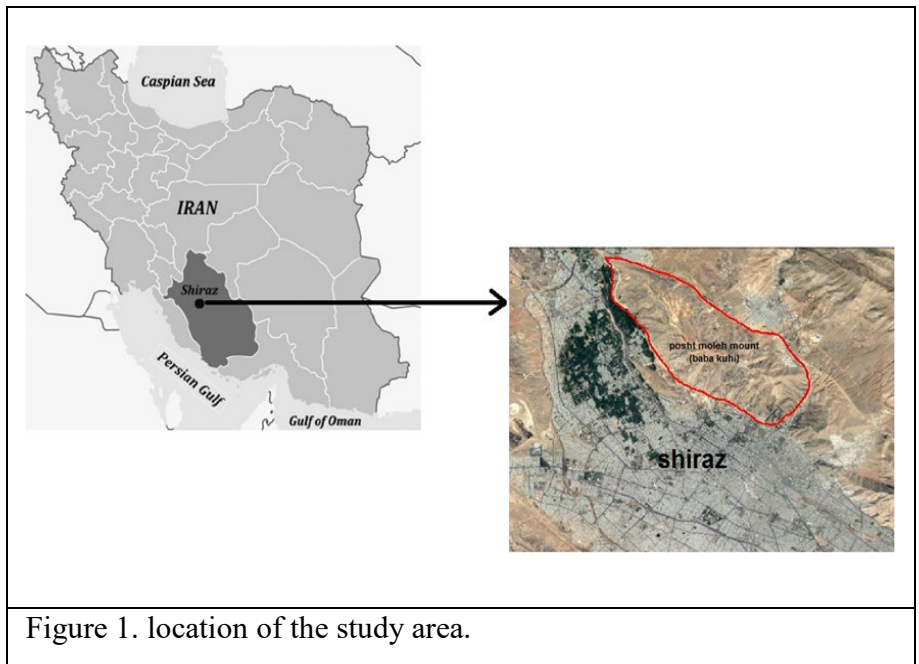




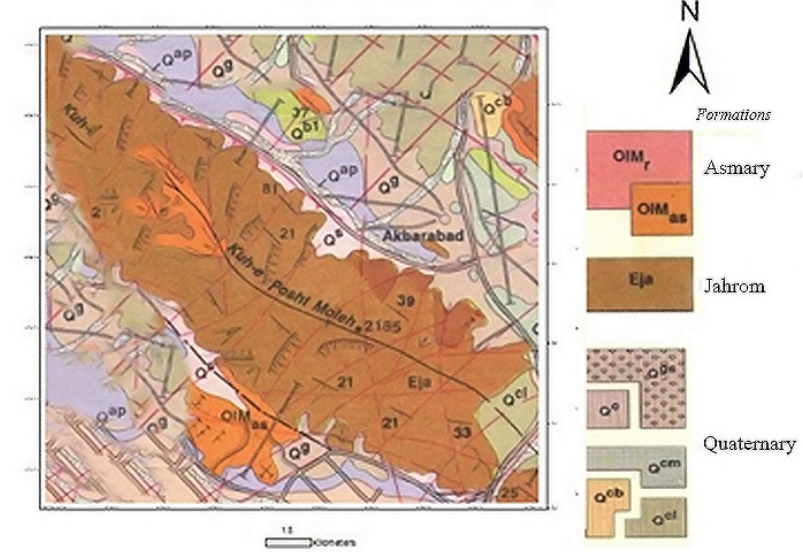

Fiigure 2. Geological map of Posht Moleh Mountain (Baba Kouhi).

\section{MATERIALS AND METHODS}

\subsection{ASTER and OLI Sensors}

The Advanced Spaceborne Thermal Emission and Reflection Radiometer (ASTER) is a Japanese sensor which is one of five remote sensory devices onboard the Terra satellite launched in 1999. The Operational Land Imager (OLI) is one of two remote sensory devices on board the Landsat 8 satellite launched in 2013.

These two datasets are applied frequently for lithological and alteration mapping especially the ASTER dataset (Ninomiya, 2002; Rockwell and Hofstra, 2008; Barnaby and Rockwel, 2009; John and Lawrenc, 2011).

In the present research, the Level 1T dataset of the ASTER sensor on August 14, 2003, and also the Level 1TP-RT dataset of the OLI sensor on August 2, 2017, have been collected. After preparation of these datasets, the DN values of the raw images were converted to the at-sensor radiance using equation 1 for ASTER and equation 2 for OLI.

Then the radiance values were converted to at-surface reflectance using dark object subtraction method (Abrams, 2002; Landsat U.S.G.S, 2015).

$$
\begin{aligned}
& \text { Radiance }=(b 1-1) * \text { gain value } \\
& \rho \lambda=M_{\mathrm{p}} * Q_{\text {cal }}+A_{\mathrm{p}}
\end{aligned}
$$

The pixels used in collecting the Z-profile spectra were selected according to the field sampling which shows in Figure 3 on the Sentinel 2 image.

The ASD library spectra were collected from the samples within the study area and then resampled to the ASTER and OLI datasets so they became ready for analysis. The library spectrum utilized in this research is from the JHU spectral library according to the mentioned datasets.

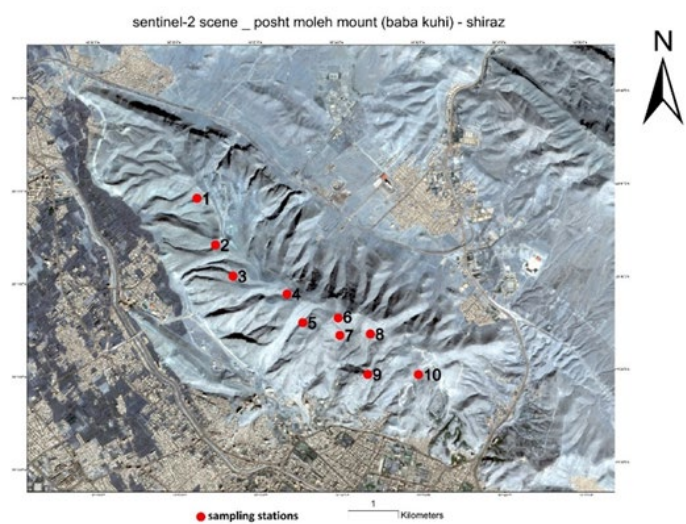

Figure 3. location of sampling stations in sentinel 2 image.

\section{RESULTS AND DISCUSSION}

The calcite minerals and rocks with the chemical composition $(\mathrm{CaCO} 3)$ have the absorption bands at $1.87,1.99,2.15$ and 2.33 $\mu \mathrm{m}$ that all of these bands are created because of the combinational and harmonic bands of vibrations of the bond $\mathrm{C}-\mathrm{O}$ in the ion composition $\mathrm{CO}_{3}{ }^{-2}$ in the reflective region of electromagnetic energy (Gupta, 2017; Clark, 1990; Hunt and Salisbury, 1975; Van der Meer, 1995).

The dolomite minerals and rocks with the chemical composition $\mathrm{CaMg}(\mathrm{CO} 3) 2$ represents the absorption bands similar to calcite with the difference that these bands are slightly displaced to shorter wavelength because of having $\mathrm{Mg}$ and they are located at the ranges of $1.86,1.98,2.13$ and $2.30 \mu \mathrm{m}$.

Briefly, in the reflectivity range of the electromagnetic spectrum, the main carbonate bands (calcite and dolomite) are in the range of 1.92 to $2.55 \mu \mathrm{m}$ (Gupta, 2017).

Considering the point that rocks are consist of minerals and other impurities associated with other factors in their formation conditions like water and organic materials, the spectrum produced from the collision of electromagnetic energy with the stone surface is the result of that stone forming particles.

It should be noticed that the rock spectrum has a completely different spectral view in contrast to the spectrum of its forming minerals, but it generally has the most important absorption and reflective features of minerals forming that rock.

The reflectivity spectrums in the short wave infrared range (1.3$2.5 \mu \mathrm{m})$ consist of some key absorption features which can be utilized in recognizing the pure and mixed calcite and dolomite to describe the ratio between calcite and dolomite (by describing the value of being dolomitized) (Clark, 1990).

The indexed absorption features of the calcite and dolomite can be distinguished by the center position of the strong vibrational absorption bands provided at 2.34 and $2.53 \mu \mathrm{m}$ for the pure calcite, and at 2.32 and $2.51 \mu \mathrm{m}$ for the pure dolomite (Vincent, 1997; Gaffey, 1985; Gaffey, 1987). 


\subsection{Analyzing the Spectral Features of the Study Area}

In analyzing the spectra achieved from the collected samples of the study area using the ASD spectrometer device, the absorption in the band 8 of the spectral range of the ASTER sensor in the library spectrum can be seen easily.

In the spectra obtained from the Z-profile of the dataset with 9 bands of the ASTER sensor, some of the spectral features mentioned for carbonates has been recorded by considering the band ranges of this sensor.

One of the spectral features recorded by the ASTER sensor in the carbonate rocks is the strong absorption in the band 8 of this sensor with the band center of $2.335 \mu \mathrm{m}$ caused by the vibration provided in the carbonate base of $\mathrm{CO} 32$ and a weak additional absorption in the band 5 with the band center of 2.167 .

Among the Z-profiles obtained from the image pixels that all of them have been extracted from the fieldwork in the study area of the image considering the geographical coordinates of the obtained samples, the pixels 2,4 and 8 in contrast to other pixels have the closest spectral to the pure carbonate spectral from the aspect of the apparent spectral view and also, by running the Spectral Analyst algorithm "which will be explained at the final section".

In the band 3 of the ASTER sensor with the band center of $0.807 \mu \mathrm{m}$, the absorption created in the image spectrum is because of the presence of ferric iron $\mathrm{Fe} 3+$ in the combination of carbonate rocks that in this band, the spectrums of pixels demonstrate considerable absorption in contrast to the band 2 with the band center of $0.661 \mu \mathrm{m}$.

Among the Z-profiles achieved from the image pixels, the pixels 1 and 7 demonstrate better representation of the iron presence in the region compared to other pixels considering the absorption depth produced in the band 3 in contrast to band 2 .

The Z-profiles extracted from the image pixels of the ASTER sensor and the ASD spectra rewritten to the spectral ranges of this sensor achieved from the samples obtained from the study area are demonstrated in the following figures.

In studying the spectra achieved from the dataset with 9 bands in the OLI sensor, the indexed features of carbonates are not recognizable considering the limitation of this sensor in the short wave infrared range. The benefit of using the OLI sensor dataset compared to ASTER sensor dataset is the bands 4 and 5 of this sensor with the band centers of 0.655 and $0.865 \mu \mathrm{m}$.

These two bands are located in the visible-near infrared range (VNIR) of the electromagnetic spectrum and considering the high radiometric separation ability of the OLI sensor with the value of 12 bits compared to the ASTER sensor with 8 bits, they have more abilities in recording the absorption caused by ferric iron.

In analyzing the spectra achieved from the OLI sensor unlike the ASTER sensor in which the NIR range was represented absorption compared to the $\mathrm{R}$ range, it does not represent any absorptions.

In the following Figures, the image spectra extracted from the dataset with 6 bands of the OLI sensor and the ASD experimental spectrum resampled to this sensor which is provided from samples obtained from the fieldwork in the study area are displayed. Figure 4 to 6 shows the spectra of samples obtained from OLI, ASTER and ASD instrument respectively.

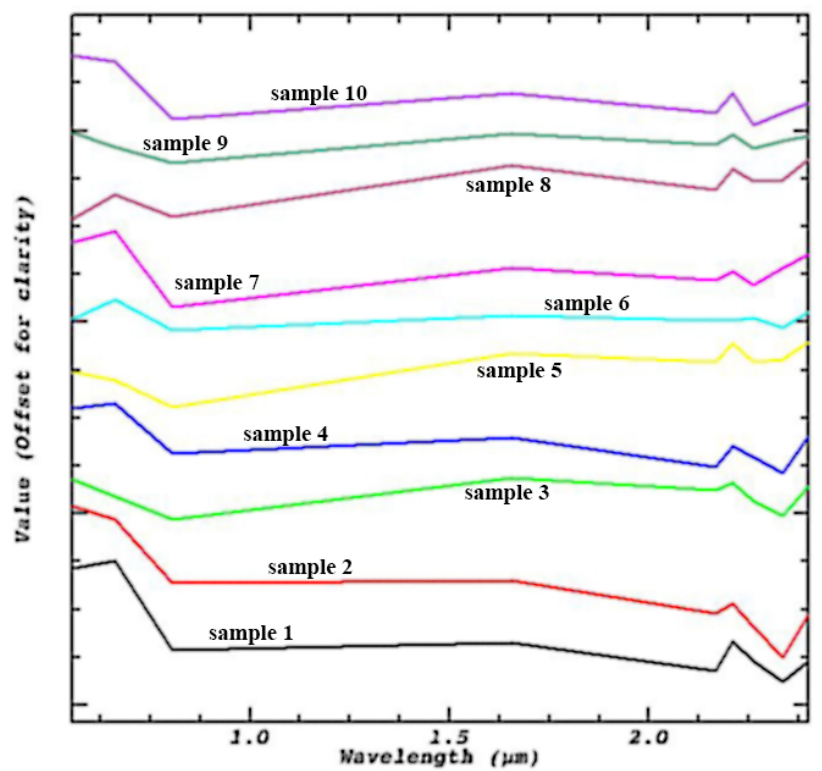

Figure 4. Z-Profile related to the locations of sampling obtained from ASTER image.

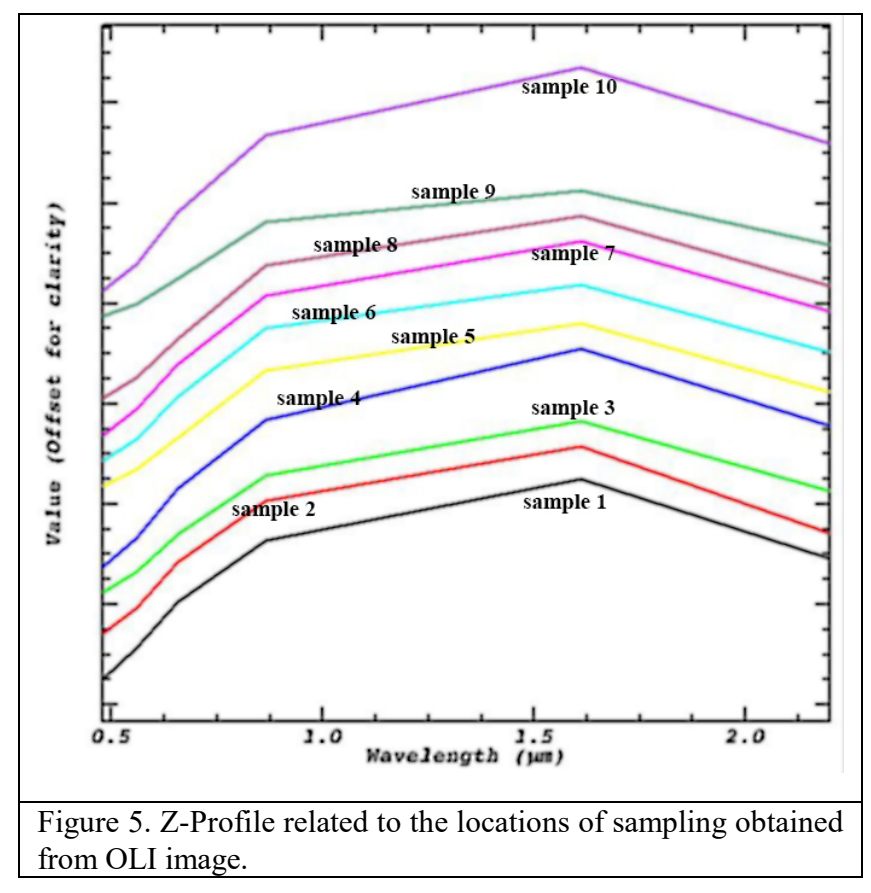




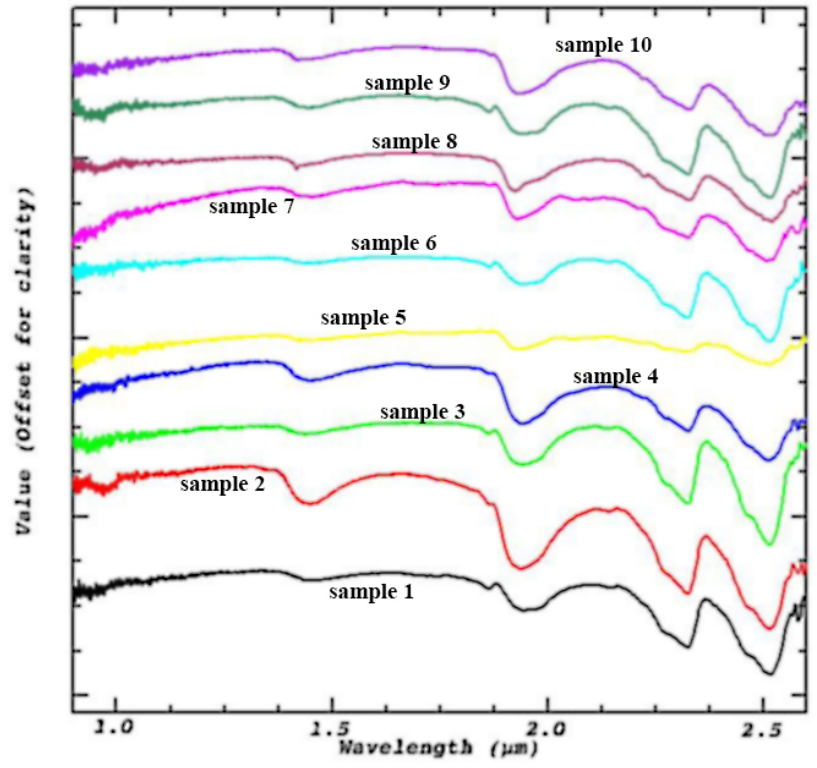

Figure 6. The spectra samples obtained by ASD instrument.

\subsection{Spectral Analyst Algorithm:}

This tool is utilized in the ENVI software to recognize the unknown spectra using a reference like the pre-prepared spectral libraries such as USGS, JPL, JHU, etc. which are used in this research. Identifying the unknown spectra using this tool is based on the spectral characteristics in the unknown spectrum and the matching scale of the unknown spectrum to the spectral library spectra.

The Spectral Analyst tool uses three techniques of Binary Encoding, Spectral Angle Mapper (SAM) and Spectral Feature Fitting (SFF) to rank the unknown spectra based on the amount of being matched with one of the spectral library spectra. The output of this algorithm is in the form of a ranked score or a given weight for each of the unknown spectra based on the input library spectrum. The highest score demonstrates the closest match and it represents the highest confidence in the spectral similarity.

\subsection{Executing the Spectral Analyst Algorithm:}

In order to execute this process considering the logic of algorithm performance, a reference is required to run the program. Because the spectra extracted from the image are the carbonate rock spectrum, a reference spectrum should be utilized which contain the carbonate rock spectrum. In the present study this algorithm based on SAM and SFF method and the JHU spectral library was used.

In order to increase the accuracy of the algorithm performance from spectra in the JHU spectral library, the spectra of carbonate rocks were extracted and recorded in the form of a spectral library with four spectra of fine-grained lime, coarsegrained lime, coarse-grained dolomitic lime and coarse-grained siltstone (Figure 7).

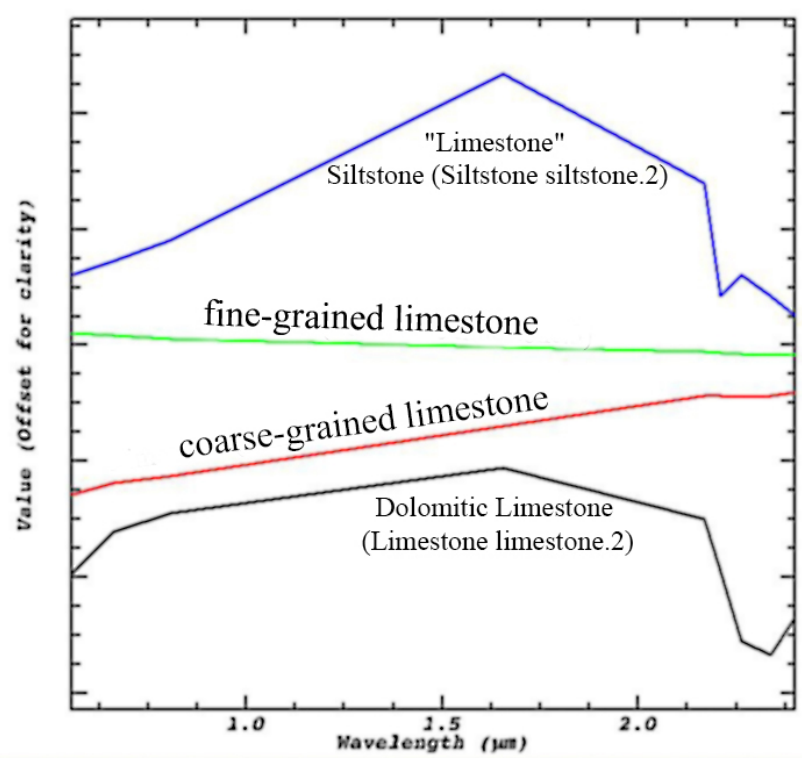

Figure 7. Carbonate spectra of the JHU library, resampled to bands of ASTER sensor.

After running the algorithm on the unknown spectra introduced into the software (Z-profile spectrum of the pixels), the algorithm in two modes of SFF and SAM introduced the coarsegrained lime spectrum as the closest spectrum of the spectral library to the input unknown spectra. When using the SFF weighing method, it introduced the pixels 6,7 and 4 with the highest score in the first to third rankings as the purest lime spectrum and the pixel spectrum 8 as the most impure lime.

When using the SAM weighing method, it introduced the pixels 2,1 and 4 in the first to third rankings and as the previous method, the pixel spectrum 8 as the most impure lime. In Figures 8 and 9 , the results of running the algorithm are displayed.

Unknown: Limestone" Siltstone (Siltstone siltstone.2)

\begin{tabular}{cccc} 
Library spectrum & SCORE & SFF \\
\hline Sample & 6 & {$[0.908]:$} & $\{0.908\}$ \\
Sample & 7 & {$[0.906]:$} & $\{0.906\}$ \\
Sample & 4 & {$[0.903]:$} & $\{0.903\}$ \\
Sample & 10 & {$[0.902]:$} & $\{0.902\}$ \\
Sample & 1 & {$[0.895]:$} & $\{0.895\}$ \\
Sample & 2 & {$[0.893]:$} & $\{0.893\}$ \\
Sample & 5 & {$[0.892]:$} & $\{0.892\}$ \\
Sample & 3 & {$[0.890]:$} & $\{0.890\}$ \\
Sample & 9 & {$[0.879]:$} & $\{0.879\}$ \\
Sample & 8 & {$[0.870]:\{0.870\}$}
\end{tabular}

Figure 8. Results of the Spectral Analyst algorithm using Spectral Feature Fitting (SFF) method. 


\begin{tabular}{|c|c|c|c|}
\hline \multicolumn{2}{|c|}{ Library spectrum } & \multirow{2}{*}{$\frac{\text { SCORE }}{[0.903]:}$} & \multirow{2}{*}{$\frac{\text { SAM }}{\{0.903\}}$} \\
\hline Sample & 2 & & \\
\hline Sample & 1 & {$[0.885]:$} & $\{0.885\}$ \\
\hline Sample & 4 & {$[0.856]:$} & $\{0.856\}$ \\
\hline Sample & 10 & {$[0.854]:$} & $\{0.854\}$ \\
\hline Sample & 7 & {$[0.835]:$} & $\{0.835\}$ \\
\hline Sample & 6 & {$[0.828]:$} & $\{0.828\}$ \\
\hline Sample & 3 & [0.824]: & $\{0.824\}$ \\
\hline Sample & 9 & [0.819]: & $\{0.819\}$ \\
\hline Sample & 5 & [0.793]: & $\{0.793\}$ \\
\hline Sample & 8 & {$[0.791]:$} & $\{0.791\}$ \\
\hline
\end{tabular}

Figure 9. Results of the Spectral Analyst algorithm using Spectral Angle Mapper(SAM) method.

\section{CONCLUSION}

After extracting the image spectra from the datasets with 9 bands of VNIR + SWIR in ASTER sensor and the 6 bands of VNIR in the OLI sensor, considering the advantage of the ASTER sensor by having 6 bands in the short wave infrared range in contrast to 2 bands in this range in OLI sensor and also, this point that minerals and stones mostly present all their spectral features in the short wave infrared range, the ASTER dataset were utilized for this reason.

\section{REFERENCES}

Abrams, M., Hook, S., \& Ramachandran, B. (2002). ASTER user handbook, version 2. Jet propulsion laboratory, 4800, 135.

Barnaby W. Rockwel (2009). Comparison of ASTER- and AVIRIS-Derived Mineral and Vegetation Maps of the White Horse Replacement Alunite Deposit and Surrounding Area, Marysvale Volcanic Field, Utah. Scientific Investigations Report 2009-5117.

Clark, R. N., King, T. V., Klejwa, M., Swayze, G. A., \& Vergo, N. (1990). High spectral resolution reflectance spectroscopy of minerals. Journal of Geophysical Research: Solid Earth, 95(B8), 12653-12680.

Gaffey, S. J. (1985). Reflectance spectroscopy in the visible and near-infrared $(0.35-2.55 \mu \mathrm{m})$ : Applications in carbonate petrology. Geology, 13(4), 270-273.

Gaffey, S. J. (1987). Spectral reflectance of carbonate minerals in the visible and near infrared $(0.35-2.55 \mathrm{um})$ : Anhydrous carbonate minerals. Journal of Geophysical Research: Solid Earth, 92(B2), 1429-1440.

Gupta, R. P. (2017). Remote sensing geology. Springer.
Hunt, G. R., \& Salisbury, J. W. (1975). Mid-Infrared Spectral Behavior of Sedimentary Rocks (No. AFCRL-TR-75-0356). AIR FORCE CAMBRIDGE RESEARCH LABS HANSCOM AFB MASS.

Landsat, U. S. G. S. (2015). 8 (18) data users handbook. LSDS1574 Version, 3.

Mars, John C.; Lawrence C. Rowan (2011). ASTER spectral analysis and lithologic mapping of the Khanneshin carbonatite volcano, Afghanistan. Geosphere.v. 7; no. 1; p. 276-289.

Ninomiya, Y. (2002, March). Mapping quartz, carbonate minerals, and mafic-ultramafic rocks using remotely sensed multispectral thermal infrared ASTER data. In Thermosense XXIV (Vol. 4710, pp. 191-203). International Society for Optics and Photonics.

Rockwell, B. W., \& Hofstra, A. H. (2008). Identification of quartz and carbonate minerals across northern Nevada using ASTER thermal infrared emissivity data-Implications for geologic mapping and mineral resource investigations in wellstudied and frontier areas. Geosphere, 4(1), 218-246.

Van der Meer, F. (1995). Spectral reflectance of carbonate mineral mixtures and bidirectional reflectance theory: Quantitative analysis techniques for application in remote sensing. Remote Sensing Reviews, 13(1-2), 67-94.

Vincent, R. K. (1997). Fundamentals of geological and environmental remote sensing (Vol. 366). Upper Saddle River, NJ: Prentice Hall. 